\section{OBSERVATIONS ON A GREEN SUN, AND ASSOCIATED PHENOMENA ${ }^{1}$}

THE rarity of the phenomenon of a green or blue sun makes it desirable to record with the greatest accuracy and detail the observations made during its appearance in India during several days of September 1883 .

The notes taken at Madras at the time of the appearance will best illustrate the general features of the phenomena:-

On September 9, the sun, bcfore setting, assumed a peculiar silvery appearance, and its brightness was so much decreased that for about half an hour before sunset it could be observed with the naked eye. This was observed, I believe, though to a less extent, on the two days preceding, but I did not myself see it on these days. On September ro, from 5 to $5.30 \mathrm{p} . \mathrm{m}$., the sun could easily be looked at with the naked eye, yet the limbs were sharply defined. At 5.30 the sun entered a low bank of clouds, and did not fully appear again; but a narrow strip seen through a rift in the cloud at 5.43 was coloured a bright pea-green. Round Madras this colour had been seen in the morning, but in Madras itself clouds concealed the sun till it had risen to a considerable altitude. Of the morning of the $I I$ th I have no record, but in the evening the green colour was brilliant, and was visible for more than half an hour, being preceded, as on the former night, by the silvery white appearance of the sun's disk. On this evening a large sunspot about $x^{\prime}$ long was so conspicuous an object that it attracted the attention of even the most casual observers.

September 12.-At $\mathbf{1 2 . 3 5}$ a.m. the moon, which was near the horizon, appeared a pale green. Bright stars near the horizon showed the same tint. From 5.15 to 5.30 the clouds to the east were coloured reddish brown. At 5.55 the sun rose with a yellowish green colour, but was almost instantly Jost in clouds. It reappeared at $6 \% 4$, and was then of a bright green colour: this colour rapidly got fainter, but was quite perceptible till 7 o'clock. In the afternoon the phenomena of the previous nights were repeated, and, the horizon being free from clouds, the actual sunset was observed. The entry in my notes is: "6.3.-The sun set as a greenish yellow ball; cumulus, stratus, and nimbus clouds near the horizon, but moon fairly clear ; some blue sky, but hazy." The change from green to greenish yellow was evidently due to the great increase in the strength of the low-sun-band close to the horizon, which left the strip of yellow between that band and the rainband by far the most prominent feature in the spectrum.

September 13.- - In the early morning there was a good deal of distant lightning. The sun rose of a bright, golden yellow colour; no green was seen. In the afternoon there were slight showers.

A most remarkable observation made this morning by $\mathrm{Mr}$. Pogson seems very difficult to explain, except by some form of auroral display. I give his notes in full :-

" 1883 . September I2, I7h. om. Madras mean time.-The sky a most remarkably intense reddish yellow, unusually bright. A dark cloud-bank from about east to south, and the vivid light above uncommonly auroral in appearance, more so than anything $I$ have seen here before.

"At I7h. Iom. the red hue considerably diministred, and bright orange yellow the prevailing tint. The light quite bright enough to make notes by.

"At I 7 h. 20m. the dark bluc-black stratum, now from about north to east, and very near the horizon. Sky tolerably clear to about $20^{\circ}$ altitude, but of a rich red tint, with bright yellow clouds above, beginning at about $30^{\circ}$, and covcring the rest of the sky.

"At I 7 h. 3om. all changed within the last four or five minutes, and writing now difficult without a lamp; a thick dark red stratum over the sunrise point, and everywhere else a very greenish yellow.

"At 17 h. 40m. the low cloud stratum now sea-green. Light only enough to write by with difficulty.

"At I 7 h. 50m., sun rising a bright yellowish white, and otherwise nothing extraordinary, all unusual tints having disappeared with the sunrise."

September 14.-Before sunrise the clouds were blue and gray, with patches of red clouds of all sorts-cirrus, nimbus, stratus, cumulus, and mares' tails. Two bright flashes of lightning about $5.30 \mathrm{a} . \mathrm{m}$. In the evening there was a slight green tinge, and

I Abstract of a paper read before the Royal Society of Edinburgh, July 7, qy Prof. C. Michie Smith. after sunset the sky was golden red till 6.50, while Mercury, seen through the red haze, was twinkling strongly.

September I5.-The sun rose golden. In the evening the sunsct was very fine : in the west the colour was golden to orangeyellow, in the east it was greenish; red clouds remained till $7 \cdot 5$. There were very brilliant red " rayons de crépuscule."

From September I 5 to September 20 the sunrises and sunsets were very fine, with red and gold, for more than half an hour before sunrise and after sunset.

September 21. - Sunset normal.

September 22. - The sun rose as a yellow ball, and showed distinct greenish yellow afterwards. From ten minutes before till sunset the sun was greenish yellow, but the sun was much brighter than on the Ioth and I Ith.

September 23. - The sun rose very green. At 5.37 p.m. the sun appeared from under clouds, very green; strong absorption in the red end of the spectrum to $\mathrm{C}$; low-sun-bands weak. 5.45.-Clouds grayish purple. There was only one bank of clouds which was near the horizon; above this was a peculiar grayish haze. At 6 the clouds were of a marked purple colour; breaks near the horizon were reddish brown. During the night there was a great deal of sheet-lightning in the south.

September 24:-The sun rose bright yellow. The spectrum showed complete absorption up to $\mathrm{B}$; the rain-band $\alpha$ and $\beta$ were very thick, and the low-sun-bands less marked than usual. There was lightning all night, beginning in the south, and working round to the south-east. It consisted chiefly of sheetlightning, with occasional zig-zag flashes, but no thunder; the stars were fairly clear except near the horizon. Saturn and the moon, when near the horizon, were both very dim.

September 25.- Sunrise golden green. In the afternoon the shadows cast on white paper were still quite pink, but the sunset was bright yellow.

September 26.- Much the same as yesterday.

September 27.-Before sunrise C, $\beta, \alpha$, the rain-band and the dry-air-band were very strong, but the dry-air-band was less than half as dark as the rain-band. The sun rose golden red. The spectrum showed signs of clearing up; glimpses of A could be obtained. After dark there was very bright lightning in the west.

September 28.-Spectrum still showed great absorption. Lightning at night.

September 29. - Spectrum absorption still very strong. After dark there was a display of luminous clouds specially towards the east. After II p.m. there was very heavy rain with much lightning and some thunder.

September 30. -Sunrise golden. The spectrum on the sun showed A clearly, a was very thick.

October 2.- In the morning from about 7 to 9 there was a thunderstorm, in which the thunder was almost continuous for about an hour and a haif, but although the storm was almost vertically overhead, hardly any lightning was visible. . . . The total rainfall for the day was 4.88 inches.

Accounts were collected from trustworthy observers in various parts of India. All describe the brilliant sunsets of the first week of September, and record the appearance of a green sun on several days. It was seen at Muttum in the south of Madras on the $g^{t h}$, and continued for several days both in the morning and the evening. The green colour was then lost, but reappeared from the 22 nd to the 28 th inclusive.

At Bellary the sun was seen "emerald-green" at rising and setting from the Ioth to the I4th inclusive. The observations were not carried on longer.

At Coonoor on the Nilgiris the abundance of green tints in the sunsets was noted, but the sun itself was merely described as of a "shimmery" appearance.

The observations at Ongole have been already noticed in Nature.

The Spectrum.-The spectrum of the sun when green was repeatedly obscrved and photographed with the large zodiacal-light spectroscope, which is furnished with one large prism of dense glass and a very long collimator permitting the use of a wide slit. The main features of the spectrum taken on the sun when green were-

I. A very strong general absorption in the red end.

2. A great development of the rain-band and of all other lines that are ascribed to the presence of water-vapour in the atmosphere, more especially of the group $C_{1}$ of $\alpha$ and of the band at W.L. 504 .

The absorption in the red end was of very varying intensity, 
but when the phenomenon was at its maximum phase it gradually crept up from about $\mathrm{B}$ till past $\mathrm{C}$, as the sun sank towards the horizon. On the I2th, when the sun was within a few degrees of the horizon, the absorption was well marked up to W.L. $62 \mathrm{I}$, i.e. to beyond $a$, while at the violet end the visible spectrum ended at W.L. 428 , or just beyond G.

The lines $\mathrm{A}$ and a were never visible even on the sun, when it was green, and even $B$ could be made out with difficulty from half an hour before sunset onwards, and before it vanished it grew intensely prominent with enormously thick bands on the less refrangible side. The band $\mathrm{C}_{1}$ on the more refrangible side of $\mathrm{C}$ became very broad and black, while the fine line between this and $\mathrm{C}$ remained thin and sharp, and $\mathrm{C}$ itself thickened out on the less refrangible side. 'The rain-band was stronger than I have ever before observed it on the plains, and even with the dispersion produced by a single prism at least eight lines could be measured in it, while many more were visible. The low-sunband was not very conspicuous, but this was partly due to contrast with the very strong rain-band. The line W.L. 568 at the more refrangible side of the low-sun-band was very well marked, and the band itself seemed to consist of a series of equidistant lines.

The apparently much stronger absorption in the red than in the blue end was a very marked feature, which became still more conspicuous when a photograph of the blue end was examined.

Since the passing away of the abnormal conditions I have made careful observations of the sunset spectrum with the same apparatus, and I find that ordinarily $\mathrm{A}$ and $a$ are clearly visible as well as B, though at times they are strongly marked, and a good deal of shading is observable between them; $\mathrm{C}_{1}$ is much thinner, and the rain-band is less prominent than the low-sunband, which however does not now have the appearance of a number of fine lines. The nearest approach to the green-sun spectrum was observed recently during a severe thunderstorm, which was accompanied by a fall of about $\mathrm{I} \frac{1}{2}$ inches of rain. A very similar though less intense spectrum can be observed almost any evening by taking advantage of the passage of a small thin cloud over the sun's disk. If a lens is used in front of the slit of the spectroscope, the absorption due to the cloud will be seen as a band in the middle of the bright spectrum from the unclouded part of the sun, and owing to the strong contrast, the details of the absorption will be well seen, just as in the case of the spectrum of a sunspot.

Meteorological Phenomena.-The electrification of the air was carefully studied during the green sun period, and the results are rather curious. From September 3 to 6 the potential of the air was positive in the early morning, diminished to zero between 9 and ro a.m., then became negative, and remained so until the sea-breeze came on in the afternoon, when the charge was positive again, and continued so all night. The amount of electrification varied greatly and rapidly. On the 7 th and 9 th the potential was positive all day, on the 8th it was negative for a short time. From the Ioth to the 12 th it varied in the same way as from the 3 rd to the 6 th, and this state of matters was repeated from the 20 th to the 27 th ; the electrometer readings from the 13th to the Igth having been normal. All the negative readings were got during a hot land wind from the west. Between the 6th and 9 th of September a storm of unusual violence swept over the Madras Presidency from the south-west to the northeast, making itself felt in different ways at different places. The rainfall for September was unusually small all over Madras. The average for fifteen stations was $3 \cdot 24$ inches, not quite half the average for this month during previous years.

The barometric curves for Colombo, Madras, Belgaum, Allahabad, and Calcutta (Alipore) have been drawn and found to resemble each other closely. All over India there was a minimum between the 6 th and the 7 th, a maximum about the I 8 th, another minimum on the $2 \mathrm{sst}$, then a rise, and a third minimum on the 27 th.

The first essential in any attempt to arrive at an explanation of the cause of the green sun is to ascertain the precise dates a which the phenomenon was first observed in various parts of the world. It is difficult to do this, for people are apt to make more precise statements than their observations warrant. For instance, the sun certainly set with a peculiar silvery gleam, but no greenness, at Madras on September 9, and yet many persons have assured me that they saw it set green there on that evening. The reason evidently was that after their attention had been arrested by the green sunsets of the Ioth and IIth they remembered having noticed something peculiar about the sunset on the 9 th, and immediately concluded that the sun had been green on that occasion also. In consequence of this tendency of the mind, the evidence for all the dates given has been carefully tested, and has been found in all cases sufficient to justify the opinion that these dates are correct.

It appears that in Ceylon, in the south part of the Madras Presidency, and at Ongole in the north, the sun was first observed to be green on the evening of the gth, and that over the east of the Presidency, when seen at all, it was first seen green on the morning of the Ioth. The green sun was reported at Belgaum on the 8th, but although the observer was trustworthy, he did not make a note of the fact until afterwards, and it is just possible that it may be a mistake.

The captain of the Cleomene reports a green sun and moon on the 9 th, Ioth, and IIth, when his position was from lat. $8^{\circ} \mathrm{N}$. to lat. $16^{\circ} \mathrm{N}$., and from long. $83^{\circ} 3 \mathrm{O}^{\prime} \mathrm{E}$. to long. $88^{\circ} 4 \mathrm{O}^{\prime} \mathrm{E}$. The chief officer of the s.s. Pelican saw the moon greenish on the night of the 9 th, and the sun green on the morning of the Ioth. The stcamer was more than 1000 miles away from Madras, in lat. $10^{\circ} 4^{\prime} \mathrm{N}$. and long. $64^{\circ} 12^{\prime} \mathrm{E}$., wind south-west.

The green sun was not seen further north than Ongole, except at Vizagapatam, Rajamundry, and Simla, and the dates of observation at these stations are not preserved. It was seen at Bombay, but was so inconspicuous that it escaped notice at the Observatory.

In Honolulu the sun's disk was seen to be green before it set on September 4 and 5 (NATURe, vol. xxix. p. 549). On September 4 the master of the Jennie Walker " noticed the strange appearance of the sun, which was greenish," in lat. $8^{\circ} 20^{\prime} \mathrm{N}$. and long. $155^{\circ} 28^{\prime} \mathrm{W}$. A passenger three days out from Honolulu for Sydney saw it blue on the $5^{\text {th }}$ and 6th (Ibid., p. I8r). On September 2 it was observed bluish green in Venezuela and in Trinidad (Ibid., vol. xxviii. p. 577, vol. xxix. p. 77). It was seen at Panama on the $2 n d$ and 3 rd, and at Cape Coast Castle apparently on the Ist of September. So much for the first appearance.

The sun was again seen green on September 20, in lat. $12^{\circ} 50^{\prime} \mathrm{N}$. and long. $48^{\circ} 26^{\prime} \mathrm{E}$. At almost all stations in Southern India the greenness reappeared on the 22nd, and Hicks Pasha noticed the sun green in the Soudan on the 24 th.

The phenomena of the green sun must be distinguished fron those of the remarkable sunsets that occurred all over the world some time later, and the reasons for considering them essentially different are :-

I. The general appearances of the sunsets were quite different. The sunsets accompanying the green sun were lurid, and the horizon so misty that stars were lost in it ; the subsequent sunsets were remarkable for the play of delicate tints, the rose-coloured after-glow, and the unusual clearness of the horizon.

2. The spectra were totally different. In the latter case the red end was unusually free from absorption; $\mathrm{A}, \mathrm{a}$, and $\mathrm{B}$ stood out clearly, the rain-band was slight, and the low-sun-bands strong. This contrasts in every way with the description of the spectrum of the green sun already given.

Three hypotheses have been put forward to account for the phenomena of the green sun :-

x. That it was duc to vapours or dust from the volcanic erup tion at Krakatao. This was at first proposed by Mr. Pogson.

2. That the cause was the presence of an abnormal amount of aqueous vapour-an explanation which $I$ offered at the time of the occurrence.

3. That it was caused by a cioud of meteoric dust.

The supporters of the Krakatao theory view the phenomena of the green sun and the remarkable sunsets as due to the same cause. The two great difficulties with regard to that hypothesis are ( $\mathrm{r}$ ) that there is no proof of the existence of an air current travelling at the enormous velocity required by the dates of the appearances of the green sun at various places, and (2) granting that there was such a current, how it was that the dust was such a long time in reaching India. Mr. Lockyer gets over these difficulties by assuming the existence of an upper current from east to west along the equator, and an under current from south to north. If, however, Mr. Manley's observations are accurate, as there seems every reason to believe they are, the green sun appeared at Ongole as soon as in Colombo, and at least twelve hours sooner than in Madras; and, if the Belgaum observations are correct, it appeared there a day before it was noticed at Colombo. Taking, however, only those observations about 
which there can be no doubt, we get the following velocities, taking the shortest lines between Krakatao and the various stations :-

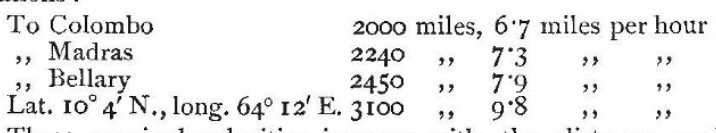

These required velocities increase with the distance, and, taking along with them the rate of forty miles an hour demanded by the Japan observations, it is difficult to believe that dust could have travelled in these various directions with such different velocities.

There is also the negative evidence that rain-water collected in Madras during the period of the green sun contained no volcanic dust, as far as a careful microscopic examination of the residue could determine it. On the dust hypothesis, too, it is difficult to understand the cessation and reappearance of the phenomenon.

There is some definite evidence on which to base the argument for the water-vapour theory. The observations detailed at the beginning of this paper show that the spectrum of the green sun had the absorption-lines of water-vapour very well marked, and that there was also a general absorption in the red. This absorption might indeed be accounted for by supposing a number of dust particles of a certain size to be suspended in the air ; but a precisely similar absorption has been observed when the sunlight traversed the very thick clouds of a violent thunderstorm. The fact that water-vapour may make the sun appear green is proved by the numerous observations of a green sun through the escaping vapour from the funnel of a steamer, and through mist. The abundance of water-vapour in suspension was proved by the very heavy monsoonal rains which followed the appearance of the green sun. In Madras the rainfall was 19.17 inches above the average.

The green sun, although uncommon, is by no means so rare a phenomenon as is generally supposed. Since my attention has been directed to it, I have observed it several times, very conspicuously on May I 3 and $I_{4}$. But there is a reason why $i$ should not appear much more frequently, and that is that, supposing the absorption producing it to be brought about by an abnormal amount of water-vapour, that vapour must be in suspension, while in fact it generally partly precipitates, forming clouds that conceal the sun as its hour of setting approaches. An interesting question arises as to whether the clearness of the atmosphere, when a large amount of aqueous vapour was in sus. pension during the appearance of the green sun, might not be due to an abnormal electrical state. The numerous and intense thunderstorms that occurred during the period showed that all the clouds were highly electrified, and the electrometer observations already referred to also indicated an unusually electrified atmosphere; but I am not prepared to lay much stress on the electrometer readings until I have made a more extended series of observations in ordinary weather.

The presence of abundance of aqueous vapour at the time of the appearance of the green sun may be explained naturally enough by the setting in of the moist monsoon currents in the upper parts of the atmosphere, or at least by the conflict between the north-east and south-west monsoons, which had commenced by that time.

It is not at all improbable that the Krakatao eraption had some influence on the direction of these currents. The ejection of a large volume of heated vapour would produce a centre of low pressure and set up a cyclonic influx of air from other places. It is possible that the peculiarities obscrved in the Indian barometric curves for some time after the eruptions were due to this cause. The cruption, too, might have something to do with the electrical conditions; for it is known from Prof. Palmieri's observations that electricity is generated by the cruptions of Vesuvius.

I was once inclined to view with favour the theory of the appearances being produced by cosmic dust, stupposing the dust to act either by its mere presence or by forming nuclei for absorption; but considerations of the amount of solar radiation during the greenness have shaken my faith in this explanation.

We must, therefore, I think, give up any theory involving the presence of sufficient dust to render the sun green. Whether or not the following sunset glows were due to dust I cannot discuss here; but I would point out that an amount of dust sufficient to produce these effects would probably not materially affect the transparency of the atmosphere.

\section{EDUCATION, SCIENCE, AND ART}

THE Select Committee of the IIouse of Commons appointed to consider how the Ministerial responsibility under which the votes for Education, Science, and Art are administered may be best secured, have agreed to the following report :-

Your Committee have examined the present and several former Presidents and Vice-Presidents of the Council, Secretaries to the Lord Lieutenant of Ireland, permanent heads of the Education Department in London, the present Resident Commissioner of National Education in Ireland, and also other gentlemen conversant with the matters referred to your Committee. They have also considered the evidence taken before the Select Committee appointed in 1865 and 1866 to inquire into the constitution of the Committee of Council on Education.

The first question considered by your Committee was whether primary cducation in Great Britain and in Ireland should be placed under one supervising Minister. Your Committee are satisfied that under present circumstances it would be undesirable to disturb the existing arrangements as to the Ministerial responsibility for primary education in Ireland.

They a e also of opinion that primary education in England and Scotland should be under the control of the same Minister.

The Lord President of the Council, almost always a peer, is nominally the head of the Education Department for Great Britain.

The Vice-President represents the department in the House of Commons, and really transacts almost all the business requiring authority above that of the permanent officials.

Your Committee are of opinion that this arrangement is neither logical nor convenient. They see no sufficient reason why there should be any more real connection between the Education Department and the Privy Council than betwe $n$ the Board of Trade and the Privy Council ; but as it may be convenient that the Mini ter for Education should have occasionally the assistance, whether as to English or Scotch Education, of other Privy Councillors specially summoned for consultation with him, they recommend that a Board of (or Committee of Ccuncil for) Education should be constituted under a President, who should be the real as well as nominal Minister, in this respect holding a position like that of the President of the Board of Trade. Hitherto there has been a separate Scotch Department of the Privy Council, and your Committee consider that it would be well to have a distinct permanent secretary appointed for Scotland, responsible to the Minister of Education.

Whether the Minister of Education should always be a member of the Cabinet or of the House of Commons, and what should be his salary, are questions upon which it is hardly within the province of your Committee to make absolute recommendations. They think, however, that the duties of this Minister should be recognised as not less important than those of some of the Secretaries of State.

The Minister of Education should have the assistance of a Parliamentary Secretary, able to sit in either House of Parliament.

While on the whole preferring the plan they have suggested, your Committee do not deny that there are objections to the constitution of an administrative department in the form of a board which has no real existence. The permanent secretary and his assistants bind by their signature, nominally the board, really, the political chief.

This system, it must be admitted, tends to lessen the direct control and responsibility to Parliament and the public which is apparent in the office of a Secretary of State.

The second question discussed by your Committee was whether, and if so what, authority should be exercised by the Minister of Education over endowed schools. Your Committee recommend that when schemes for endowed schools, whether in England or in Scotland, have come into operation, the Minister of Education should have full authority to call on the governing bodies to furnish him with such reports and information as he may require, and to direct any inquiries or inspection to be made which he may deem necessary.

$\Lambda$ s to public schools, your Committee recommend that the Minister of Education should be authorised to call for such reports and information as he may require from the governing bodies, but they are not of opinion that his powers should extend to directing inspection.

With respect to the Universitics in Great Britain receiving grants charged on the votes of Parliament or on the Consolidated 